\title{
The Dead Space After Extirpation of Rectum. Current Management and Searching for New Materials for Filling
}

\author{
M. BOCKOVÁ ${ }^{1}$, J. HOCH ${ }^{1}$, A. KESTLEROVÁ ${ }^{2,3}$, E. AMLER ${ }^{2,4,5}$ \\ ${ }^{1}$ Department of Surgery, Second Faculty of Medicine, Charles University in Prague and Motol \\ Faculty Hospital, Prague, Czech Republic, ${ }^{2}$ Department of Biophysics, Second Faculty of Medicine, \\ Charles University, Prague, Czech Republic, ${ }^{3}$ Institute of Biophysics and Informatics, First Faculty \\ of Medicine, Charles University, Prague, Czech Republic, ${ }^{4}$ Czech Technical University in Prague, \\ Faculty of Biomedical Engineering, Kladno, Czech Republic, ${ }^{5}$ Czech Technical University in \\ Prague, University Centre for Energy Efficient Buildings, Buštěhrad, Czech Republic
}

Received October 31, 2019

Accepted December 11, 2019

\section{Summary}

Pelvic surgeries such as extirpation of the rectum or pelvic exenteration lead to a creation of a dead space, which can be cause of complication, such as bowel obstruction, perineal hernia, abscess or hematoma. A growing incidence of complication is expected in connection with the increasing use of laparoscopic and robotic approaches or ELAPE method. Since the bone structures do not allow compression, the only way to deal with the dead space is to fill it in. Present methods provide the filling with omental or myofascial flaps. The length and the mobility of the omental flap can be the limitation. Myofascial flaps are technically more demanding and bring the complications of a donor place. Synthetic or biological meshes do not deal with dead space problematic. Modern technologies using nanomaterials offer the possibility to produce a material with specific properties for example shape, inner structure, surface, or time of degradation. The modified material could also satisfy the requirements for filling the dead space after surgeries.

\section{Key words}

Dead space in pelvis - Extirpation of rectum • Biological mesh • Nanomaterials

\section{Corresponding author}

M. Bocková, Národní obrany 10, Praha 6, 16000, Czech Republic. E-mail: bockova.marketa@gmail.com

\section{Introduction}

Dead space is a cavity remaining after surgical procedures when the operative wound is closed. This can happen when tissue is removed, after the evacuation of fluid collections, after surgical dissection or as a result of a trauma. In the dead space, the accumulation of interstitial fluid and blood occurs, representing a possible cause of later complications. Specific complications occur in the area of the chest and pelvis.

There are two types of dead spaces with slightly different management. Firstly, there are cavities with elastic and compressible walls. Such dead space can be eliminated by drainage or compression. The latter are cavities after extirpation in pelvis. The bone walls of pelvis are not elastic and the volume of the postoperative dead space cannot be reduced. Since the rigidity of the walls does not allow compression of the dead space, it should be filled with material which will prevent accumulation of fluids and dislocation of other structures into the dead space. Particularly, in the area of the pelvis, the filling material should prevent the descent of the small intestine and the emergence of postoperative ileus.

\section{Dead space in the pelvis}

After surgical procedures in the pelvis, 
especially following removal of the rectum, bladder or multivisceral resection, a dead space arises. The dead space may be a cause of postoperative complications. The most common complication is bowel obstruction, when the small intestine descends into the dead space and bowel obstruction develops (Fig. 1).

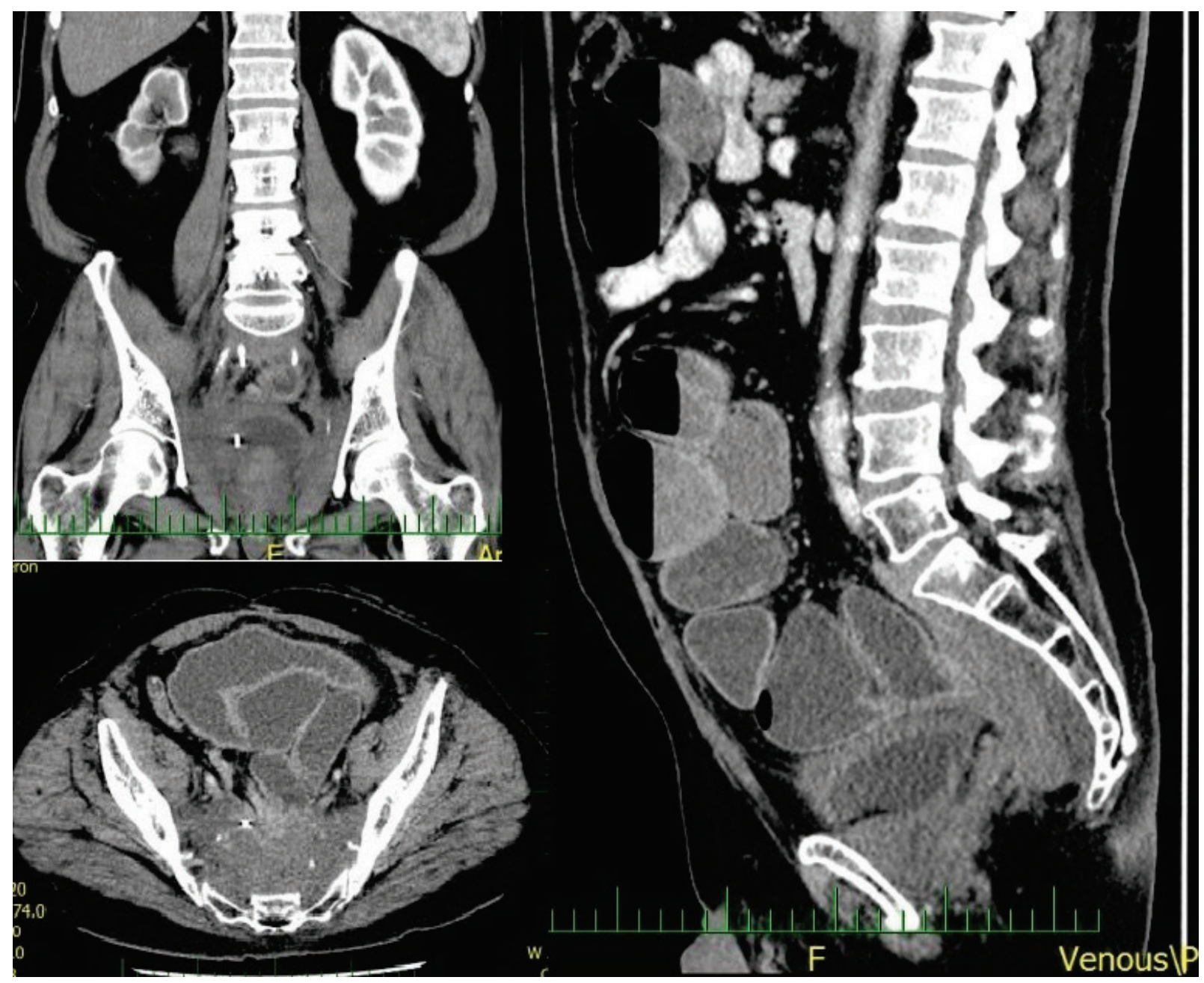

Fig. 1. CT scan of a patient 3 years after extirpation of the rectum due to an adenocarcinoma. Small bowel is fixed to the infiltrate in the pelvis. The patient suffers from a recurrent partial bowel obstruction. (Author's archive, 2019)

If the convolute of the loops pushes through the perineum, a perineal hernia develops. A risk of strangulation or the formation of an enteral fistula emerges. All the fluids concentrate in the dead space cavity, a hematoma or an abscess can cause problems.

Growing incidence of complication is expected in connection with an increasing use of modern methods. Laparoscopic or robotic approaches lead to a decreased formation of adhesion in the upper part of the abdomen cavity, so the small bowel is more mobile and it is able to descent easily in the pelvic cavity. On the other hand, the wound area or the neoadjuvant radiations in the pelvic region favors the adhesion formation. ELAPE (Extra Levator Amputation of Rectum) results in a greater defect in the pelvic floor so the impaired perineal wound healing appears more often (West et al. 2008, Musters et al. 2017).

Dealing with the complications is a challenge, the problems relapse very often, operation risks for patients increase with every other intervention. Also the economic factors of the treatment cannot be missed.

\section{Characteristics of the dead space after rectum removal}

The size and volume of the space left after the surgical procedure depends mainly on the volume of the removed organ, the type of the surgery, the patient's gender and BMI. The rectum is most often removed due to a malignant tumor. The rectum is $12-16 \mathrm{~cm}$ long, 
approx. $4 \mathrm{~cm}$ wide tube. The location and boundary of the dead space in the pelvis is given by the following description. The rectum passes through the pelvic cavity, which is delimited by the pelvic brim (inlet) above and the pelvic floor (outlet) below (Fig. 2). Pelvic inlet is an ideal plane between the promontory of sacral bone and the upper edge of pubic bone. Besides the rectum, pelvic cavity contains bladder and prostate in male and uterus with ovaries and tubes in female. The organs are covered by the peritoneum from the cranial side and they are supported from the caudal side by the pelvic floor, the muscular bottom of the pelvis that is formed mainly by the levator ani muscle (Fig. 2). The male pelvis is narrower and deeper than the female pelvis.

The rectum is removed together with the mesorectum, which contains lymph nodes, nerves and vascular plexus. The volume of the mesorectum is the largest on the dorsal side and it narrows in the ventral side. In the craniocaudal direction, the mesorectum is the thickest in the middle part. During the abdominoperineal amputation of the rectum (APE), the resection line leads just outside of the sphincter complex. In the case of an extralevator amputation of the rectum (ELAPE), a part of the levator muscle is also resected, the formed defect is larger and its closure is more difficult. It follows that the space arising after the removal of the rectum has a shape of a cylinder of a length of $15-20 \mathrm{~cm}$ and a diameter of $6-8 \mathrm{~cm}$. The pelvic organs and the extent of the pathological involvement can be visualized by CT or MRI (Fig. 3). These examinations already allow to measure the size of the rectum and to estimate the size of the resulting defect after the surgery. Futhermore, more accurate space volumetry, color differentiation of organs in the pelvis, and $3 \mathrm{D}$ reconstruction can be obtained using various computer programs (Fig. 4) (Sahnan et al. 2018).

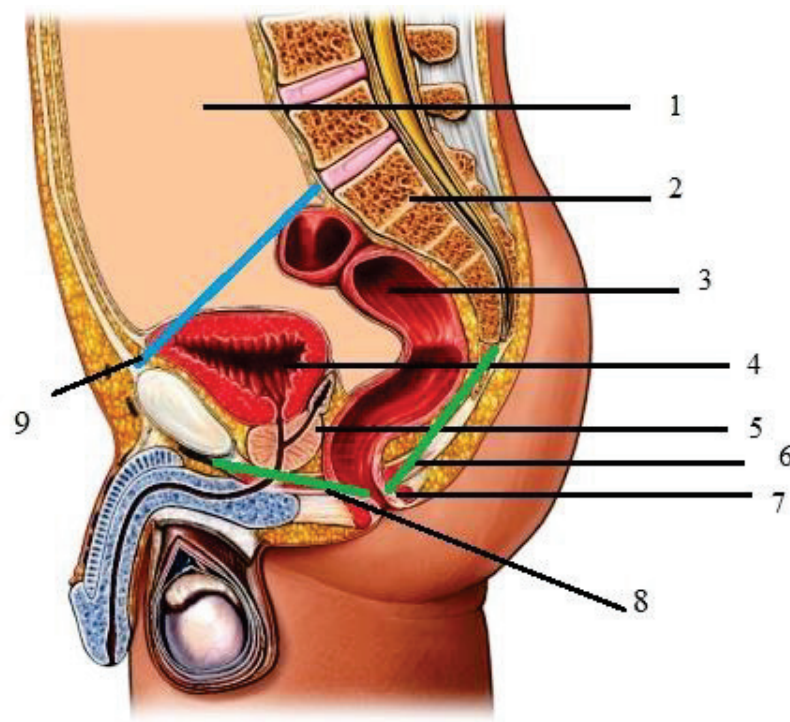

Fig. 2. Sagittal view of male pelvis, scheme. 1. Abdominal cavity; 2. Sacrum; 3. Rectum; 4. Bladder; 5. Prostate; 6. Levator ani muscle; 7. Anal sphincter muscle; 8 Pelvic floor; 9 Pelvic inlet. (Adapted from Nucleus Medical Media, 2020)

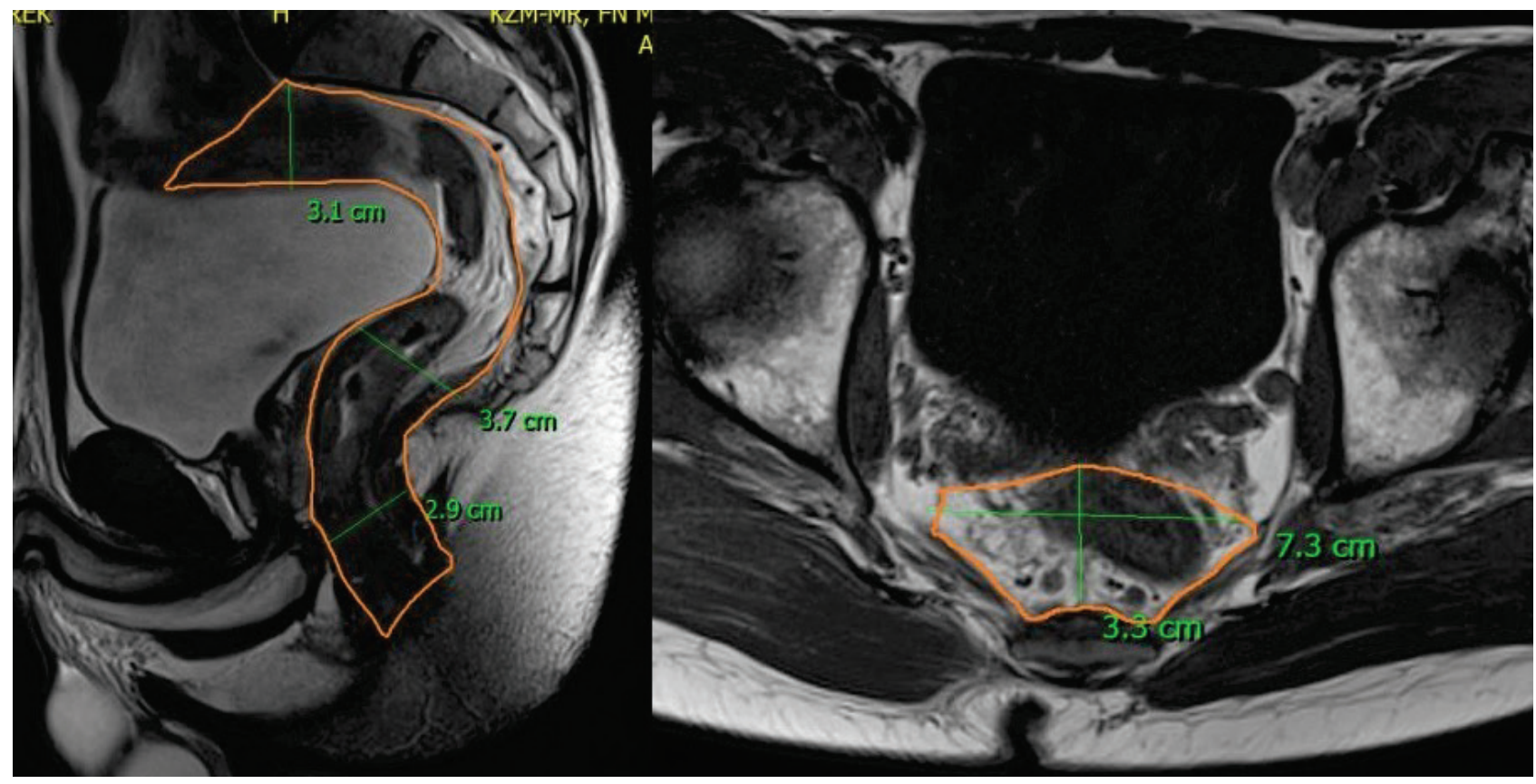

Fig. 3. Pre-operative MRI of a patient with a malignant tumor of the rectum with outlined edges of the rectum and mesorectum. (Author's archive, 2019) 

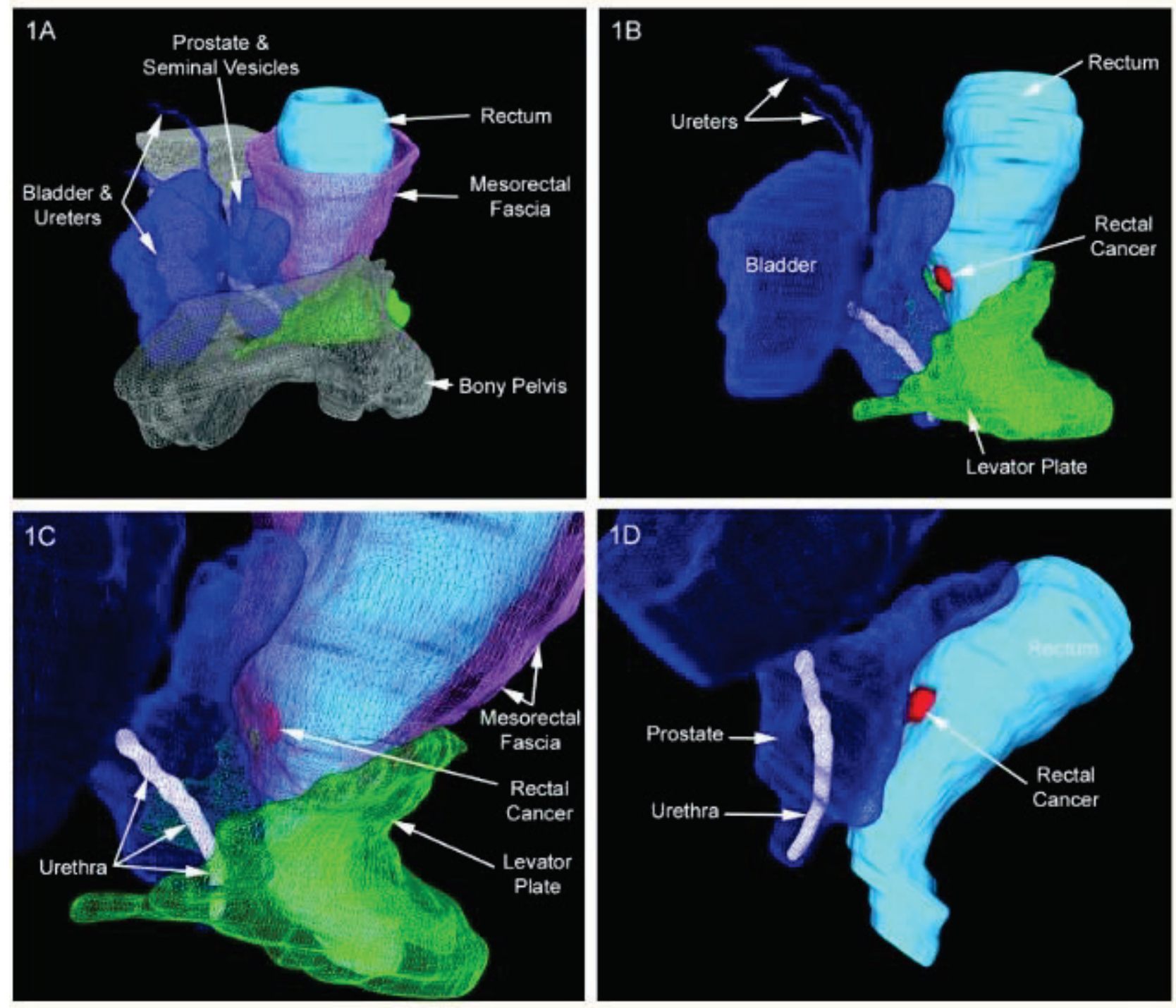

Fig. 4. Example of a 3D view. (Sahnan et al. 2018)

\section{Current options of pelvic floor closure and dead space filling}

To close the pelvic floor, the dead space in pelvis and the perineum defects, structures of the body or artificial implants are exploited. The techniques used are primary suture, plastic surgery using muscular or musculocutaneous flaps and omentoplasty. Rarely, other body organs for example an uterus or a urinary bladder can be used. The use of adipose tissue-derived stem cells is currently under research (Takahashi et al. 2012). Among artificial implants, meshes are most often being implanted.

The primary suture is feasible only if sufficient amount of a suitable material is available. A high risk of complications of healing of the perineal wound is reported in $18-34 \%$ of the cases (Killeen et al.2013).
For the omentoplasty, the limiting factor can be the length and volume of the omentum, particularly in asthenic patients, and its mobility. The risks include complications from the loss of vitality of the dislocated omentum (Killeen et al.2013). Muscular and musculocutaneus flaps of rectus abdominis muscle, gracilis muscle or gluteus maximus muscle are a possible but complicated solution (Brodbec et al.2015, Chong et al. 2015, Hoch and Jech 2000). Meshes allow the closure of the pelvic floor, however, there may be a risk associated with the implantation of a foreign material and the formation of enteral fistulas. A polytetrafluoroethylene mesh (Cui et al 2009) or fully resorbable copolymer mesh from polyglycolic acid and trimethylurite (Moreno-Sanz et al. 2011) are synthetic meshes that have been used. Because of concerns of infectious complications, their use is receding. Biological 
meshes appeared after the year 2005 (Murphy et al. 2005). They are based on xenogeneic implants from porcine dermal collagen, intestinal submucosal and bovine pericardium. Allogeneic implants are made of human acellular dermal matrix. It is declared that the biological meshes can be used even in contaminated environments, the risk of developing intestinal fistulas is lower than the risk associated with the use of synthetic meshes (Marshal et al. 2014, Alam et al. 2016, Schilz et al. 2017, Fitzgerald et al. 2017). These positives should compensate the higher price of the biological meshes. Yet they are the cause of complications. E.g. Musters (2017) indicates that $10 \%$ of the 50 patients had to be treated for a perineal abscess, $37 \%$ of patients suffered from complicated healing of the perineal wound and perineal hernia was detected in $13 \%$ of patients after 1 year of observation. The necessity of removing the mesh has been recorded in only 1 of the 216 patients reported in the 7 largest papers on the topic

It should be emphasized that the mesh allows only closing the pelvic outlet, but it doesn't affect the dead space (Fig. 5).

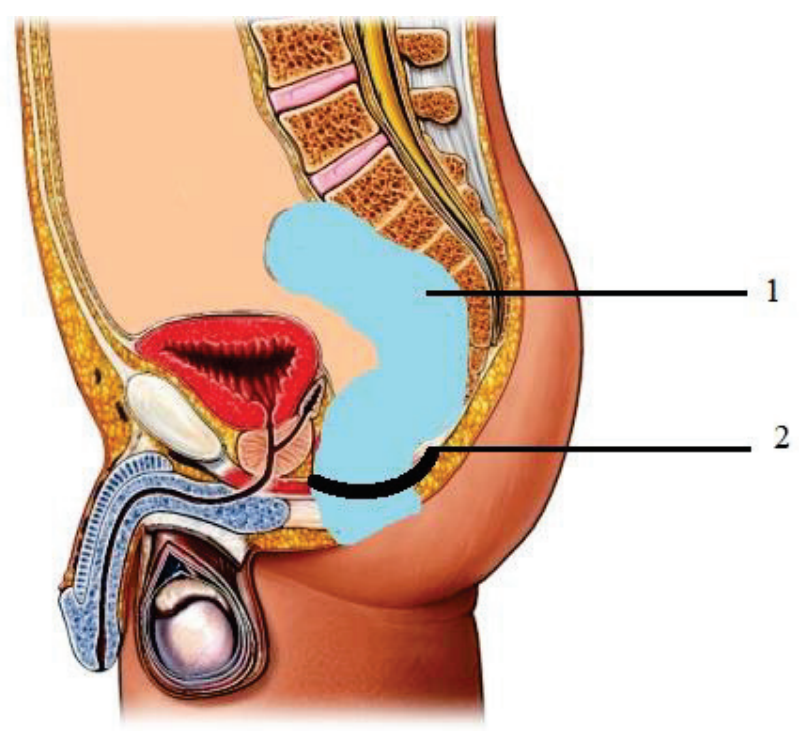

Fig. 5. Diagram of the situation after the implantation of the mesh. The dead space above the mesh remains.1.Dead space after rectal extirpation; 2. Implanted mesh. (Adapted from Nucleus Medical Media, 2020)

\section{Materials already used and searching for new possibilities}

The characteristic of all biomaterials is defined by their physico-chemical-biological properties, in particular the shape, surface, internal structure, composition, biostability and biocompatibility, i.e. by interaction of materials in a biological environment. The ideal biomaterial is completely biocompatible, meaning it does not cause an inflammatory reaction. It is not thrombogenic, toxic, allergenic, carcinogenic, mutagenic or teratogenic. Such a material is still being looked for. The material has to be biostable, it must maintain its properties for the period of use in the organism and, in the long term, its biodegradability is desired, so in time it can be replaced by the body's own tissues.

Biomaterials are classified as synthetic or organic. In abdominal surgery, the most often used synthetic biomaterials are polymers (non-resorbable polypropylene, polyester, polytetrafluoroethylene, polyamides or resorbable - polylactide-glycolide, polycaprolactone, polyanhydrides, collagen, glycosaminoglycans, hydrogels). The organic biomaterials include allografts (human acellular dermal matrix) and xenografts (from porcine dermal collagen, intestinal submucosal and bovine pericardium). Polymers with shape memory have been developed. These polymers may be applied in a liquid form; then, they will morph into the desired shape when they are already inside the body. For a long time, organic materials have been preferred over synthetic ones. It seems advantageous to imitate as much as possible the three-dimensional structure of the extracellular matrix, which provides a suitable environment for body's own or implanted cells (Binyamin et al. 2003, Cobb et al. 2009, Gaharwar et al. 2014) Other technologies can be used to prepare composite materials with several different functions. Nanotechnology can modify the surface, enrich the internal structure of the material and achieve specific properties and precisely targeted functions (Binyamin et al. 2003). Thus, the modified material could also satisfy the requirements for filling the dead space after surgeries.

\section{Conclusion}

The aim of this work is to draw attention to the problem of dead space formed in the pelvis after rectum removal and to the possibilities to prevent this problem. The next step is to create and test a suitable biodegradable nanofibrous material, which will be sufficiently biocompatible and will allow filling the dead area in the pelvis. Furthermore, the material will be strong enough to prevent dislocation of other structures into the pelvis and will inhibit adhesions on the surface. Also, the internal structure of the material will support fibrous tissue production in order to be eventually 
replaced with the body's own tissue.

\section{Conflict of Interest}

There is no conflict of interest.

\section{Acknowledgements}

The study was supported by the Internal Grant Agency of the Ministry of Health of the Czech Republic (MZ-VES project no. 16-29680A).

\section{References}

ALAM NN, NARANT SK, KOCKERLING F, DANIELS IR, SMART NJ: Biologic mesh reconstruction of the pelvic floor after extralevator abdominoperineal excision: a systematic review. Front Surg 3: 9, 2016.

BINYAMIN G, SHAFI BM, MERY CM: Biomaterials: a primer for surgeons. Semin Pediatr Surg 15: 276-283, 2003.

BRODBEC, R, HORCH RE, ARKUDAS A, BEIER JP: Plastic and reconstructive surgery in the treatment of oncological perineal and genital defects. Front Oncol 5: 212, 2015.

COBB WE, PEINDL RM, ZEREY M, CARBONEL AM, HENIFORD BT: Mesh terminology 101. Hernia 13: 1-6, 2009.

CUI J, MA JP, XIANG J, LUO YX, CAI SR, HUANG YH, WANG JP, HE YL: Prospective study of reconstructing pelvic floor with GORE-TEX Dual Mesh in abdominoperineal resection. Chin Med J 122: 2138-2141, 2009.

FITZGERALD JF, KUMAR AS: Biologic versus synthetic mesh reinforcement. What are the Pros and Cons? Clin Colon Rectal Surg 27: 140-148, 2014.

GAHARWAR AK, PEPPAS NA, KHADEMHOSSEINI A: Nanocomposite hydrogels for biomedical applications. Biotechnol Bioeng 11: 441-453, 2014.

HOCH J, JECH Z: Diagnosis and treatment of pelvic and perineal defects and fistulae and reconstructive surgery using a gluteus maximus flap. Rozhl Chir 79: 633-635, 2000.

CHONG TW, BALCH HC, KEHOE SM, MARQUILIS V, SAINT-CYR MC: Reconstruction of large perineal and pelvic wounds using gracilis muscle flaps. Ann Surg Onco 22: 3738-3744, 2015.

KILLEEN S, DEVANEY A, MANNION M, MARTIN ST, WINTER DC: Omental pedicle flaps following proctectomy: a systematic review. Colorectal Dis. 15: 634-645, 2013.

MARSHALL MJ, SMART NJ, DANIELS IR: Biologic meshes in perineal reconstruction following extra-levator abdominoperineal excision (ELAPE). Colorectal Dis 03: 12-18, 2012.

MORENO-SANZ C, MANZANERA-DIAZ M, CORTINA-OLIVA FJ, DE PEDRO-CONAL J, CLERVEUS M, PICAZO-YESTE J: Pelvic reconstruction after abdominoperineal resection: a pilot study using an absorbable synthetic prosthesis. Tech Coloproctol 15: 55-459, 2011.

MURPHY EMA, CROXFORD MA, DANIEL M, MORAN BJ, GOLS DM: A novel pelvic floor closure technique using porcine dermal collagen after abdomino-perineal excision of the rectum [ECCP/EACP Abstract 024]. Colorectal Dis 7: 7, 2005.

MUSTERS GD, KLAVER CEL, BOSKER RJJ, BURGER JWA, VAN DUIJVENDIK P, VAN ETTEN B, VAN GELOVEN AAW, DE GRAAF EJR, HOFF C, LEIJTENS JWA, RUTTEN HJT, SINGH B, VUYLSTEKE RJCLM, DE WILT JHW, DIIKGRAAF MGW, BEMELMAN WA, TANIS PJ: Biological mesh closure of the pelvic floor after extralevator abdominoperineal resection for rectal cancer: a multicenter randomized controlled trial (the BIOPEX-study). Ann Surg 265: 1074-1081, 2017.

NUCLEUS MEDICAL MEDIA. "Male Pelvis: cross section." Smart Imagebase. 3 Apr 2009 10:20 EDT. Nucleus Medical Media 9 Jan 2020.

SAHNAN K, PELLINO G, ADEGBOLA SO, TOZER PJ, CHANDRASINGE P, MISKOVIC D, HOMPES R, WARUSAVITAME J, LUNG PFC: Development of a model of three-dimensional imaging for the preoperative planning of TaTME. Tech Coloproctol 22: 59-63, 2018.

SCHILZ B, BUCHS NCH, PENNA M, SCARPA CR, LIOT E, MOREL P, RIS F: Biological mesh reconstruction of the pelvic floor following abdominoperineal excision for cancer: A review. World J Clin Oncol 8: 249-254, 2017. 
TAKAHASHI H, HARAQUICHI N, NISHIKAWA S, MIYAZAKI S, SUZUKI Y, MIZUSHIMA T, NISHIMURA J, TAKMASA I, YAMAMOTO H, MIMORI K, ISHII H, DOKI Y, MORI M, TKASHASHI H, HARAQUICHI N, NISHIKAWA S, MIYAZAKI S, SUZUKI Y, MIZUSHIMA T, NISHIMURA J, TAKEMASA I, YAMAMOTO H, MIMORI K, ISCHII H, DOKI YM, MORI M: Biological and clinical availability of adipose-derived stem cells for pelvic dead space repair. Stem Cells Transl Med 1: 803-810, 2012.

WEST NP, FINAN PJ, ANDERIN C, LINDHOLM J, HOLM T, QUIRKE P: Evidence of the oncologic superiority of cylindrical abdominoperineal excision for low rectal cancer. J Clin Oncol 26: 3517-3522, 2008. 